\title{
Predictors of somatic symptoms: a five year follow up of adolescents
}

\author{
K Poikolainen, T Aalto-Setälä, M Marttunen, A Tuulio-Henriksson, J Lönnqvist
}

\begin{abstract}
Background-Somatisation is common among adolescents.

Aims-To study factors predicting somatisation later in adulthood.

Methods-Self report questionnaires were administered at baseline examination in 1990 to students (mean age 16.8 years) in schools, and by mail five years later. Results are based on the 615 subjects with no serious disease or injury at baseline. Results-Regression analyses showed that in men the level of somatic symptoms in 1995 was significantly predicted by the respective level in 1990 and by relief smoking. In women, the level of somatic symptoms in 1995 was significantly predicted by the respective level in 1990, self esteem, and the number of negative life events in 1990. After exclusion of cases with a long standing disease in 1995, the multivariate results remained materially similar except that self esteem was no longer significant among women.

Conclusion-These findings may help in early identification of adolescents with somatisation persisting into early adulthood.

(Arch Dis Child 2000;83:388-392)
\end{abstract}

Keywords: adolescence; life change events; smoking; somatoform disorders

Somatic symptoms are common among adolescents. ${ }^{1-10}$ Although these symptoms are only rarely associated with organic disease in adolescence, ${ }^{7}$ the symptoms are frequently an expression of the inability to recognise own emotions (alexithymia). ${ }^{5}$ Somatic symptoms seem to be clinically important warning signs, ${ }^{5}$ which may persist into adulthood, herald later mental disorder, ${ }^{11}$ and lead into high use of health services. Adults with abridged somatisation disorder diagnosis have been found to have more anxiety symptoms, depression symptoms, and physical disability than other adults. ${ }^{12}$ In one study, health care costs among patients prone to somatisation have been estimated to be ninefold compared with the average patient. ${ }^{13}$ Thus, efforts aiming at early identification of persistent somatisation might be useful in prevention of mental disorder and reduction of unnecessary health services use. Using self reports of frequent somatic symptoms in the absence of self reported serious disease as an approximation to somatisation, we have studied whether somatisation in young adulthood can be predicted by somatisation and other factors present in adolescence.

\section{Subjects and methods}

SUBJECTS

The present cohort comprised students from five high schools in Helsinki and five in Jyväskylä, Finland. The five schools in Jyväskylä, a city of about 60000 inhabitants in central Finland, comprised all schools in that city except the newest one. In Helsinki, the capital of Finland with approximately 500000 inhabitants, five schools were sampled from a total of 33, stratifying for different levels of school entrance requirements.

In 1990, students were asked to fill in a self administered questionnaire, supervised by research assistants, during a regular classroom hour. Teachers were not present. The students were free to refuse to answer, to respond anonymously, or to give their written consent to take part in the follow up examination. The number of subjects with approved questionnaires was 1493, of whom 784 responded anonymously and 709 volunteered for the follow up. The follow up group did not significantly differ from the anonymous one with respect to social class, grade point average, and the factors measured in this follow up, except for the number of somatic symptoms. In both boys and girls, anonymous respondents reported less somatic symptoms than did those who identified themselves. The absolute difference in the symptom score was not very large, however. The mean scores (SE) were 22.8 $(0.29)$ and $21.8(0.22)$ for men, and 25.0 $(0.23)$ and $24.2(0.23)$ for women. Of the volunteered group, one had died and two questionnaires had to be rejected. Thus, the number of subjects in this follow up study was 706. Of these, $264(37.4 \%)$ were men and 442 $(62.6 \%)$ women. In 1995, a follow up questionnaire and up to four reminders were mailed; 649 questionnaires were returned. The response rate was $92 \%$.

Fourteen men and 20 women were excluded from the present analysis because they had a serious illness or injury in 1990. Of the remaining cases, 33 men and 24 women were excluded because of deficient responses to questions on somatic symptoms in 1995. This left 615 subjects for analysis (fig 1 ).

\section{MEASURES}

Somatic symptom score was an abbreviated 14 item version of an 18 item score, used earlier in studies on both adults and adolescents. ${ }^{414} \mathrm{We}$ left out a question on the lack of sexual desire because this was thought to be too sensitive for the adolescents in 1990. We also left out questions about anxiety or nervousness, nightmares, and irritability or fits of anger because of coinciding questions in the trait anxiety inven- 


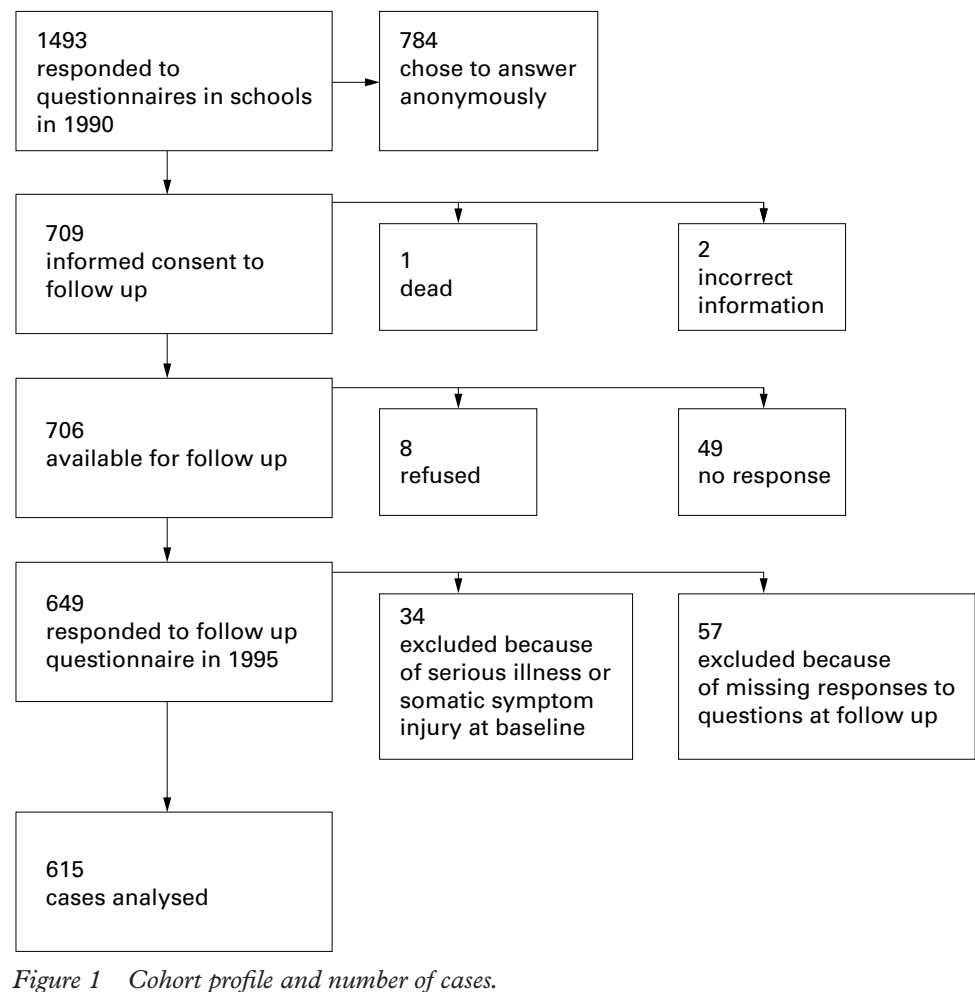

Figure 1 Cohort profile and number of cases.

tory. Response options and scoring for items were (1) never, (2) occasionally, (3) rather frequently, and (4) frequently. In order to examine frequent occurrence of symptoms the last two categories were combined. Subjects were asked to report symptoms that had occurred during the past six months.

Social class assessment was based either on father's occupation or on mother's occupation in cases where the father was not living in the family of the adolescent. The City of Helsinki social group classification has the following four groups: (I) professionals, managers, and higher administrative or clerical employees; (II) lower clerical employees; (III) skilled workers; and (IV) unskilled workers.

Academic achievement was documented by the grade point average on the final school report card. This is awarded at the end of the 9 th grade when most students are 15 years old.

Social support was ascertained by asking "Do you have a significant other person with whom you may discuss your personal activities and problems?". "Yes" was scored 1, "no" 0. The question for the perceived degree of social support, "How important is this person to you?" was measured on a seven point Likert scale. An abbreviated version of the Life Event Checklist ${ }^{15}$ consisted of 20 defined life events (items 1-8, 12-13, 16, 19, 22, 30-31, 34-35, 37) considered most common among Finnish adolescents and of four open items.

The State-Trait Anxiety Inventory ${ }^{16}$ was used to measure trait anxiety, a general tendency of feeling. Trait depression was assessed by two questions following the style, scoring, and response options of the StateTrait Anxiety Inventory. The questions dealt with a general tendency to have manifest depressive mood. ${ }^{17}$ We had to confine ourselves to these two questions as some items in commonly used measures of depression were included in the State-Trait Anxiety Inventory or in the Symptoms Score. The self esteem scale by Rosenberg ${ }^{18}$ consists of 10 items measuring the self acceptance aspect of self esteem. Additive scoring was used.

The Defence Style Questionnaire (DSQ) consisted of 72 statements on a nine point scale assessing possible conscious derivatives of 20 defences. ${ }^{19}{ }^{20}$ Based on the 88 item original, it has been revised to be congruous with the definitions of defence mechanisms in the Diagnostic and statistical manual of mental disorders (DSM-III-R) by the American Psychiatric Association. ${ }^{21}$ As in earlier research, these defences were combined into three variables: (1) mature defences (anticipation, humour, sublimation, and suppression); (2) neurotic defences (altruism, idealisation, and reaction formation and undoing); and (3) immature defences (acting out, autistic fantasy, denial, devaluation, displacement, dissociation, isolation, passive aggression, projection, rationalisation, somatisation, and splitting). Earlier, a test-retest study found that the defence styles correlated closely when the DSQ was repeated six months later in a sample of 39 cases.

Relief alcohol or drug use and relief smoking, two items from DSQ, were used as independent variables to measure substance use. These were "I take drugs, medicine, or alcohol when I am tense" and "I smoke when I am nervous". The items were removed from the immature defense style score. This did not notably weaken the immature defence style score; the correlation coefficient between the original and the abridged score was over 0.99 for both girls and boys.

STATISTICAL ANALYSIS

Between group differences in the distributions of continuous variables were assessed with the two tailed $t$ test. Associations between categorical variables were assessed with the $\chi^{2}$ test. If less than two thirds of the items for a composite scale were missing, missing values were replaced by the mean value, calculated from the items answered by the respondent. The sensitivity of results to this was studied by excluding and including cases with replaced values in the analysis.

Multivariate models were fitted to evaluate the relations between dependent variables and the dependent variable. In the case of a continuous dependent variable, regression analysis was used, in the case of a categorical one logistic regression. Interactions were studied by adding product terms. The level of significance was set at $\mathrm{p}<0.05$.

\section{Results}

In 1995, one or more somatic symptoms were reported frequently (including the response option "rather frequently") by $24 \%$ of the men and $44 \%$ of the women. Persistence of symptoms was studied by examining the number of cases who reported frequent occurrence of one or more symptoms both in 1990 and in 1995 . Of all men reporting somatisation 
Table 1 Frequency of occurrence of one or more somatic symptoms in 1990 and 1995 in men and women

\begin{tabular}{|c|c|c|c|c|c|}
\hline \multirow[b]{2}{*}{ Gender } & \multirow{2}{*}{$\begin{array}{l}\text { Symptoms in } \\
1990\end{array}$} & \multicolumn{2}{|c|}{ Symptoms in 1995} & \multirow[b]{2}{*}{$O R$} & \multirow[b]{2}{*}{$95 \% C I$} \\
\hline & & Yes (\%) & No (\%) & & \\
\hline \multirow{2}{*}{ Male } & Yes & 67.3 & 41.0 & \multirow[t]{2}{*}{2.97} & \multirow{2}{*}{$1.54-5.72$} \\
\hline & No & $\begin{array}{l}32.7 \\
(52)\end{array}$ & $\begin{array}{l}59.0 \\
(166)\end{array}$ & & \\
\hline \multirow[t]{2}{*}{ Female } & Yes & 78.2 & 58.3 & \multirow[t]{2}{*}{2.56} & \multirow{2}{*}{$1.64-4.01$} \\
\hline & No & $\begin{array}{l}21.8 \\
(174)\end{array}$ & $\begin{array}{l}41.7 \\
(223)\end{array}$ & & \\
\hline
\end{tabular}

Number of cases in parentheses.

$\mathrm{OR}$, odds ratio.

Table 2 Frequency of somatic symptoms in 1995 in men and women

\begin{tabular}{lcc}
\hline & Men $\%$ & Women $\%$ \\
\hline Headache & 3.7 & 13.4 \\
Abdominal pains & 2.8 & 7.8 \\
Fatigue or weakness & 3.7 & 14.9 \\
Lethargy & 6.0 & 13.1 \\
Difficulty in falling asleep or waking up during the night & 9.2 & 9.3 \\
Lack of appetite & 1.4 & 1.8 \\
Dizziness & 1.8 & 3.0 \\
Diarrhoea or irregular bowel function & 3.7 & 12.3 \\
Nausea or vomiting & 0.5 & 1.3 \\
Heartburn or dyspepsia & 3.2 & 7.3 \\
Profuse perspiration in the absence of physical effort & - & 3.0 \\
Hand tremor & 0.9 & 2.8 \\
Tachycardia or irregular heart rhythm & - & 2.5 \\
Dyspnoea in the absence of physical effort & 218 & 3.0 \\
Number of cases & & 397 \\
\hline
\end{tabular}

Table 3 Correlation coefficients ( $r$ ) between the somatic symptom score in 1995 and baseline variables in 1990

\begin{tabular}{|c|c|c|c|c|}
\hline \multirow[b]{2}{*}{ Variables in 1990} & \multicolumn{2}{|l|}{ Men } & \multicolumn{2}{|l|}{ Women } \\
\hline & $r$ & $n$ & $r$ & $n$ \\
\hline Somatic symptom score & $0.45^{\star \star \star}$ & 218 & $0.42^{\star \star \star}$ & 397 \\
\hline Trait anxiety & $0.34^{\star \star \star \star}$ & 218 & $0.26^{\star \star \star}$ & 396 \\
\hline Perceived social support & -0.004 & 193 & -0.06 & 382 \\
\hline Negative life events & 0.06 & 218 & $0.21^{\star \star \star}$ & 397 \\
\hline Self esteem & $-0.22^{\star \star \star}$ & 218 & $-0.26^{\star \star \star}$ & 397 \\
\hline Grade point average & -0.10 & 217 & -0.04 & 396 \\
\hline Relief drinking & $0.25^{\star \star \star}$ & 217 & $0.25^{\star \star \star}$ & 395 \\
\hline Relief smoking & $0.16^{\star}$ & 217 & $0.17^{\star \star \star}$ & 395 \\
\hline \multicolumn{5}{|l|}{ Defence style scores } \\
\hline Mature & -0.07 & 216 & 0.003 & 396 \\
\hline Neurotic & $0.16^{\star \star}$ & 216 & $0.15^{\star \star}$ & 395 \\
\hline Immature & $0.20^{\star \star}$ & 216 & $0.25^{\star \star \star}$ & 396 \\
\hline
\end{tabular}

${ }^{\star} \mathrm{p}<0.05 ;{ }^{\star \star} \mathrm{p}<0.01 ;{ }^{\star \star \star} \mathrm{p}<0.001 ; \mathrm{n}=$ number of cases.

Table 4 Regression analysis of somatic symptom score in 1995 on predictors in 1990 in 218 men and 397 women

\begin{tabular}{|c|c|c|c|c|c|c|}
\hline \multirow[b]{2}{*}{ Gender } & \multirow[b]{2}{*}{ Predictor in 1990} & \multicolumn{2}{|c|}{ Regression coefficient } & \multirow[b]{2}{*}{ tvalue } & \multirow[b]{2}{*}{ p value } & \multirow[b]{2}{*}{$R^{2}$} \\
\hline & & Estimate & $\begin{array}{l}\text { Standard } \\
\text { error }\end{array}$ & & & \\
\hline \multirow[t]{3}{*}{ Men } & Somatic symptom score & 0.352 & 0.049 & 7.184 & $<0.001$ & \\
\hline & Relief smoking & 0.157 & 0.066 & 2.383 & 0.018 & \\
\hline & Constant & 10.519 & 1.041 & 10.108 & $<0.001$ & 0.23 \\
\hline \multirow{4}{*}{ Women } & Somatic symptom score & 0.328 & 0.045 & 7.354 & $<0.001$ & \\
\hline & Negative life event score & 0.219 & 0.091 & 2.394 & 0.017 & \\
\hline & Self esteem & -0.110 & 0.044 & 2.521 & 0.012 & \\
\hline & Constant & 15.917 & 1.871 & 8.507 & $<0.001$ & 0.21 \\
\hline
\end{tabular}

Table 5 Regression analysis of somatic symptom score in 1995 on predictors in 1990 in 189 men and 322 women with no long standing disease in 1995

\begin{tabular}{|c|c|c|c|c|c|c|}
\hline \multirow[b]{2}{*}{ Gender } & \multirow[b]{2}{*}{ Predictor in 1990} & \multicolumn{2}{|c|}{ Regression coefficient } & \multirow[b]{2}{*}{$t$ value } & \multirow[b]{2}{*}{$p$ value } & \multirow[b]{2}{*}{$R^{2}$} \\
\hline & & Estimate & $\begin{array}{l}\text { Standard } \\
\text { error }\end{array}$ & & & \\
\hline \multirow[t]{3}{*}{ Men } & Somatic symptom score & 0.315 & 0.053 & 5.938 & $<0.001$ & \\
\hline & Relief smoking & 0.160 & 0.071 & 2.266 & 0.025 & \\
\hline & Constant & 11.244 & 1.111 & 10.120 & $<0.001$ & 0.19 \\
\hline \multirow[t]{4}{*}{ Women } & Somatic symptom score & 0.326 & 0.048 & 6.837 & $<0.001$ & \\
\hline & Negative life event score & 0.224 & 0.094 & 2.379 & 0.018 & \\
\hline & Self esteem & -0.074 & 0.046 & 1.625 & 0.105 & \\
\hline & Constant & 14.640 & 1.965 & 7.449 & $<0.001$ & 0.20 \\
\hline
\end{tabular}

at this level in 1995, 67\% reported symptoms already in 1990 . The respective figure for women was $78 \%$. In bivariate analysis, frequent symptoms in 1990 predicted significantly the presence of frequent symptoms in 1995 in both sexes (table 1). The most common symptoms occurring frequently included fatigue or weakness, lethargy, sleeping difficulties, headache, abdominal pain, and diarrhoea or irregular bowel function (table 2).

Multivariate regression analysis was used to examine in more detail potential predictors of the symptom level in 1995. The former included social group, perceived degree of social support, trait anxiety, trait depression, number of worries, number of negative life events, self esteem, grade point average, relief drinking, relief smoking, the three defence style clusters (immature, neurotic, and mature) and somatic symptom score in 1990. Many of the former correlated significantly with the somatic symptom level in 1995 (table 3). However, when the latter were entered as continuous explaining variables in regression models with the somatic symptoms score in 1995 as the dependent variable, only a few remained significant.

In men, the level of somatic symptoms in 1995 was significantly predicted by the respective level in 1990 and by relief smoking. In women, the level of somatic symptoms in 1995 was significantly predicted by the respective level in 1990 as well as by self esteem and the number of negative life events in 1990 (table 4). There were no interactions between the predictors. When the number of negative life events was replaced in the model by the individual 22 negative life event items, none of the latter reached statistical significance. However, increased parental absence from home $(p=0.10)$, loss of employment by parent $(\mathrm{p}=0.11)$, and failing in an examination $(\mathrm{p}=0.26)$ were the three most important single items. The results did not materially change when the predictors were examined as categorised variables in logistic regression analysis. The cut off point for the categorised variables was the 67 th percentile.

In 1995, the presence of a long standing disease was reported by $13 \%$ of the men and $19 \%$ of the women. The most frequent of these were allergy in 30 cases, asthma in 14 cases, dermatological diseases in 10 cases, and diabetes in eight cases. After exclusion of all cases who reported a long standing disease, the multivariate results remained materially similar except that self esteem was no longer a significant predictor among women (table 5).

\section{Discussion}

We found notable continuity in somatic symptoms between adolescence and early adulthood. Given the frequent symptoms in 1990, the odds ratio for reporting frequent symptoms in 1995 was threefold for men and 2.6-fold for women, compared with subjects with occasional or no symptoms in 1990. Among our subjects with frequent somatic symptoms at the follow up examination, $67 \%$ of the men and $78 \%$ of the women had already had frequent 
symptoms five years earlier as adolescents. Multivariate regression analysis confirmed that the continuity of somatic symptoms was not confounded by other predictors. To our knowledge, this is the first follow up study on the continuity of somatic symptoms from adolescence to early adulthood in a population sample. A one year follow up study on symptom levels in a consecutive clinical series has previously been reported. ${ }^{22}$

Earlier cross sectional studies, including our own, have found several factors that correlate with the level of somatic symptoms. ${ }^{7023}$ In prospective design, however, only a few of these predict the level of somatic symptoms at follow up, suggesting that the remaining factors are not causally independent and thus not relevant to changes in the symptom score. In our earlier cross sectional analysis in adolescence, somatic symptom scores associated positively with trait anxiety, trait depression, immature defence style, and alcohol or drug use in both sexes. ${ }^{10}$ In boys, smoking was associated with more symptoms, and in girls, high self esteem with fewer symptoms. In the present prospective analysis, the level of somatic symptoms in 1995 was significantly predicted by the respective level in 1990 and by relief smoking in men. In women, the level of somatic symptoms in 1995 was significantly predicted by the respective level in 1990 and the number of negative life events in 1990.

It is interesting that the level of somatic symptoms was predicted by relief smoking in men. Compared with women, men are less good at verbally expressing psychiatric problems, and more likely to express the latter as somatic symptoms. Relief smoking may be an effort to self medicate anxiety. However, while the effect of relief smoking was statistically significant, it was not very large in absolute terms.

There are several limitations to our study. We were not able to study somatisation among the parents of the study subjects. Earlier, higher levels of somatic complaints have been found to be predicted in both adolescent boys and girls by having a father with high level of somatic symptoms in a one year follow up study of a consecutive series of children and adolescents aged $6-18$ years admitted to a paediatric clinic because of abdominal pain of at least one month's duration. Moreover, the level of somatic symptoms in boys correlated positively with those of their mothers. ${ }^{22}$ These findings might reflect genetic influences or learning from parental example. The importance of the genetic component is supported by a follow up study on 335 twins from birth to the age of $12-20$ years. Zygosity was unfortunately not measured but the concordance of somatic symptoms was $93 \%$ in boy-boy pairs, $91 \%$ in girl-girl pairs, and $71 \%$ in boy-girl pairs, suggesting genetic inheritance. ${ }^{24}$ Further studies should assess the familial background of somatisation more closely.

Our study was based on self reports. These may be subject to errors caused by forgetting and conscious or unconscious faking. We used self reports of frequent somatic symptoms in the absence of self reported serious disease as an approximation of somatisation. Somatisation is defined as the presence of medically unexplained symptoms. ${ }^{12}$ Ideally, the assessment should be based on medical examination and exclusion of disease. Unfortunately, this was not possible in our study. However, we could exclude all cases who reported a long standing disease in 1995.

The number of negative life events in adolescence predicted the level of somatic symptoms in adulthood in women. As no single life event reached significance, it seems that it is the cumulative exposure to negative events that is important in the causation of somatic symptoms. However, a larger study might find small significant effects of single negative events.

The previously mentioned one year follow up study ${ }^{22}$ also found that a high level of somatic symptoms was predicted by having higher levels of negative life events in cases with low social competence. We did not have a measure of social competence. A related concept is, however, self esteem. We found that both self esteem and the number of negative life events predicted somatic symptom levels in women. There was no interaction between negative life events and self esteem in our data. However, self esteem was no longer a significant predictor among women after exclusion cases who reported a long standing disease.

The number of subjects with somatisation is likely to be overestimated in our study. Approximately one half of the students gave their consent for follow up at baseline, and those who preferred to respond anonymously reported on average a lower level of somatic symptoms than the rest. The mean difference in symptom score was not large, however. The mean score for men remaining anonymous was $4 \%$ lower than that for participants. The respective figure for women was 3\%. Therefore, we believe that the degree of overestimation is unimportant.

Our sample comprised urban Finnish speaking adolescents, sharing a similar ethnic, educational, and social background. In Finland, almost two thirds of the annual birth cohort at this age enter high school and schooling is free. These schools correspond approximately to British higher secondary schools. Our sample thus represents the more educated majority of Finnish adolescents. Because of the lack of the less educated third of the population and cultural variation, these results should be seen as suggestive rather than directly generalisable to other population groups.

To sum up, high levels of somatic symptoms in early adulthood were predicted by high somatic symptom levels in adolescence, and moreover, by a high degree of relief smoking in men and by a high number of negative life events and low self esteem in women. These findings might be useful in early identification of subjects in whom somatic symptoms persist into early adulthood. Further studies should assess more closely the predictive value of the above measures and the familial background in the continuity of somatic symptoms and exam- 
ine possibilities for early interventions to reduce somatisation.

This work was supported by a grant from the Signe and Ane Gyllenberg Foundation.

1 Rimpelä $M$, Rimpelä A, Pasanen M. Koetut oireet 12-18-vuotiailla suomalaisilla (English summary: Per12-18-vuotiailla suomalaisilla (English summary: Per-
ceived symptoms among 12-18 year-old Finns). Sosiaalceived symptoms among 12-18
ilääk Aikak 1982;19:219-33.

2 Aro H, Paronen O, Aro S. Psychosomatic symptoms among 14-16 year old Finnish adolescents. Soc Psychiatry $1987 ; 22: 171-6$

3 Choquet $M$, Menke $H$. Development of self-perceived risk behaviour and psychosomatic symptoms in adolescents: a longitudinal approach. F Adolesc 1987;10:291-308

4 Aro H. Stress, development and psychosomatic symptoms in adolescence. Acta Universitatis Tamperensis ser A, vol. 242. Tampere: University of Tampere, 1988.

5 Smith MS. Psychosomatic symptoms in adolescence. Med Clin North Am 1990;74:1121-34.

6 Alfven $\mathrm{G}$. The covariation of common psychosomatic symptoms among children from socio-economically differing residential areas. An epidemiological study. Acta Paediatr 1993;82:484-7.

7 Greene JW, Walker LS, Hickson G, Thompson J. Stressful life events and somatic complaints in adolescents. Pediatrics 1985;75:19-22.

8 Walker LS, Garber J, Greene JW. Somatic complaints in pediatric patients: a prospective study of the role of negative life events, child social and academic competence, and parental somatic symtoms. F Consult Clin Psychol 1994;62:1213-21.

9 Walker LS, Greene JW. Negative life events, psychosocia resources, and psychophysiological symptoms in adolescents. F Clin Child Psychol 1987;16:29-36.

10 Poikolainen K, Kanerva R, Lönnqvist J. Life events and other risk factors for somatic symptoms in adolescence. Pediatrics 1995;96:59-63.

11 Thomas CB, McGabe OL. Precursors of premature disease and death: habits of nervous tension. Fohns Hopkins Med $\mathcal{F}$ 1980;147:137-45.
12 Escobar JI, Gara M, Silver RC, Waitzkin H, Holman A, Compton W. Somatisation disorder in primary care. $\mathrm{Br} \mathcal{F}$ Psychiatry 1998;173:262-6.

13 Smith GR, Monson RA, Ray DC. Patients with multiple unexplained symptoms. Arch Intern Med 1986;146:60-72.

14 Aro S. Stress, morbidity, and health-related behaviour. Scand F Soc Med 1981:(suppl 25).

15 Johnson JH, McCutcheon SM. Assessing life stress in older children and adolescents: preliminary findings with the Life Events Checklist. In: Sarason IG, Spielberger CD, eds. Stress and anxiety, Vol. VII. Washington, DC: Hemisphere Publishing, 1980:111-25.

16 Spielberger CD, Gorsuch RL, Lushene RE. STAI manual for the state-trait anxiety inventory. Palo Alto: Consulting Psychologists Press, 1970.

17 Broadman K, Erdmann AJ, Wolff HG. Cornell Medical Index health questionnaire. Manual (revised 1956). New York: Cornell University Medical College, 1956.

18 Rosenberg M. Society and the adolescent self-image. Princeton, NJ: Princeton University Press, 1965.

19 Bond MD. An empirical study of defense styles. In: Vaillant $\mathrm{GE}$, ed. Empirical studies of ego mechanisms of defense. Washington, DC: American Psychiatric Press, 1986:1-29.

20 Andrews G, Pollock C, Stewart G. The determination of defense style by questionnaire. Arch Gen Psychiatry 1989;46:455-60.

21 American Psychiatric Association. Diagnostic and statistical manual of mental disorders, 3rd edition, revised. Washington, DC: American Psychiatric Association, 1987.

22 Walker LS, Garber J, Greene JW. Somatic complaints in pediatric patients: a prospective study of the role of negative life events, child social and academic competence, and parental somatic symtoms. F Consult Clin Psychol 1994; 62:1213-21.

23 Compas BE, Slavin LA, Wagner BM, Vannatta K. Relationship of life events and social support with psychological
dysfunction among adolescents. Fournal of Youth Adolesdysfunction among adol
cence $1986 ; 15: 205-21$.

24 Moilanen I. Psychosomatic symptoms in adolescent twins. Psychother Psychosom 1991;56:88-93. 